Dikirim: 6 April 2016 Diterbitkan: 1 Januari 2017

\title{
Persepsi masyarakat kota Bima terhadap inisiasi kawasan tanpa rokok di terminal Dara
}

\section{Bima community perceptions on initiation of non-smoking area in Dara terminal}

Zahratul Hayati ${ }^{1}$, Yayi Suryo Prabandari ${ }^{1}$, Trisasi Lestari ${ }^{2}$

\begin{abstract}
Purpose: This study aimed to determine the passengers' perceptions about the effort to authorize Dara terminal of Bima city as a non-smoking area. Methods: This study was a qualitative research with a phenomenological approach. Data were collected by observation in August for 2 weeks and through in-depth interviews with 20 informants among terminal users. Data were analyzed using content analysis technique. Results: Terminal users understand that: (1) smoking can cause serious illness and even can cause death, (2) the public are benefited from the terminal as a non-smoking area, because they can access the terminal without fear of the exposure, and (3) cooperation is needed with other parties to reduce the number of smokers in the terminal. Obstacles that may be present in this effort to authorize the non-smoking area are smoking habits in the terminal which are considered normal and traders who feel threatened because cigarette smoking is the goods that are often bought by smokers in the terminal. A non-smoking area is considered can be implemented if the regulation is realistic, well socialized to people, and the communities obey to the regulation. Conclusions: The initiation of a non-smoking area in Dara terminal of Bima City can be accomplished if there is a policy of non-smoking areas, in cooperation with relevant parties and followed by a thorough socialization so that people who access the terminal can determine and adhere to the non-smoking area policies that will be formed.
\end{abstract}

Keywords: smoking habit; non-smoking area; terminal

\footnotetext{
${ }^{1}$ Departemen Perilaku Kesehatan, Lingkungan dan Kedokteran Sosial, Fakultas Kedokteran, Universitas Gadjah Mada

(Email: zahratulhayati_fkmuh@rocketmail.com)

${ }^{2}$ Departemen Kebijakan dan Manajemen Kesehatan, Fakultas Kedokteran, Universitas Gadjah Mada
} 


\section{PENDAHULUAN}

Perilaku merokok menjadi kebiasaan masyarakat. Tembakau membunuh hingga 6 juta orang per tahun dan menjadi penyebab lebih dari setengah triliun dolar kerusakan ekonomi. World Health Organization (WHO) melaporkan 6 langkah pengendalian tembakau yang paling efektif yaitu memonitor penggunaan tembakau dan pencegahan dengan kebijakan; melindungi orang dari asap rokok; menawarkan bantuan untuk berhenti menggunakan tembakau, memperingati orang tentang bahaya tembakau; menegakkan larangan pada iklan rokok, promosi dan sponsor oleh perusahaan rokok; menaikkan pajak produk tembakau. Langkah-langkah ini membantu negara untuk mengurangi penyakit terkait, kecacatan dan kematian akibat penggunaan tembakau (1). Perilaku merokok umum dilakukan dengan berbagai alasan seperti dapat menghilangkan stres, agar terlihat jantan, atau iseng saja, alasan lain agar terlihat keren, dapat menimbulkan perasaan relaks, menjadi lebih terkenal dan terlihat muda $(2,3)$.

Teori health belief model menjelaskan persepsi yang dimiliki masyarakat. Persepsi terbagi menjadi persepsi keparahan penyakit (perceived severity), persepsi kerentanan (perceived susceptibility), persepsi manfaat (perceived benefit), persepsi hambatan (perceived barrier), prasyarat dalam melakukan tindakan (cues to action), dan self efficacy. Persepsi-persepsi tersebut berguna untuk faktor-faktor yang dapat memengaruhi perilaku seseorang, termasuk perilaku masyarakat dalam upaya menginisiasi kawasan tanpa rokok (4).

Penerapan kawasan tanpa rokok (KTR) di Nusa Tenggara Barat, terutama di kota Bima, masih dalam taraf sosialisasi. Masih banyak area yang seharusnya merupakan kawasan penerapan KTR belum tersentuh sama sekali, salah satunya adalah terminal Dara kota Bima. Selain belum diterapkan KTR di terminal Dara, KTR diharapkan menertibkan perokok dan mencegah asap rokok yang dihasilkan tidak terhirup oleh orang lain yang bukan perokok. Penelitian ini bertujuan mengetahui persepsi masyarakat kota Bima mengenai upaya inisiasi kawasan tanpa rokok di kota Bima Nusa Tenggara Barat.

\section{METODE}

Penelitian kualitatif ini menggunakan pendekatan fenomenologi. Pengumpulan data pada penelitian ini dengan cara wawancara mendalam menggunakan panduan wawancara, observasi perilaku merokok masyarakat yang mengakses terminal.
Responden disesuaikan dengan pertimbangan lama beraktifitas dan lama menggunakan fasilitas terminal. Wawancara dilakukan sebanyak 1-3 kali dan selama 60-90 menit. Observasi dilakukan selama 2 minggu, pukul 07.30 WITA mulai terminal beraktivitas hingga pukul 20.00 WITA. Observasi dilakukan di area yang sering dijumpai perokok. Observasi meliputi cara memperoleh rokok (in door, dalam bus, area parkir, halaman terminal), cara membeli rokok (dibeli di warung, dibawa sendiri, diminta dari orang lain, diberikan orang lain), kebiasaan merokok (langsung merokok tanpa mempedulikan lingkungan sekitar, merokok dengan cara menghindar supaya tidak mengganggu orang lain, berpindah tempat merokok jika ditegur), jumlah batang rokok yang dihisap dalam 1 waktu rokok (1 batang, 2 batang, 3 batang atau $>3$ batang), sampai tindakan setelah responden merokok (dibuang sembarangan atau di tempat sampah/asbak).

Analisis data yang digunakan dalam penelitian ini adalah content analysis. Langkah-langkah antara lain membuat kategori atas informasi yang diperoleh (open coding), memilih kategori dan menempatkan dalam satu model teoritis (axial coding), kemudian dirangkai dalam sebuah cerita dari hubungan antara kategori (selective coding). Selain itu, hasil observasi akan diikutsertakan dalam analisis data untuk melengkapi dan menguatkan hasil wawancara dalam narasi (5).

Strategi validitas data yang diterapkan adalah dengan melakukan triangulasi sumber-sumber data terhadap hasil wawancara mendalam dan observasi dilakukan member checking untuk mengklarifikasi hasil wawancara. Selain itu, dilakukan peer review/peer debriefing segala yang berkaitan dengan keseluruhan proses penelitian kemudian dibahas bersama untuk mendapatkan hasil yang sesuai (5).

\section{HASIL}

Inisiasi kawasan tanpa rokok di kota Bima terutama di terminal Dara kota Bima bisa saja diwujudkan. Hal ini, sesuai dengan hasil temuan berdasarkan persepsi persepsi dari responden.

Persepsi masyarakat tentang ancaman penyakit akibat rokok

Perokok dan non perokok percaya bahwa ancaman penyakit akibat rokok. Rokok menyebabkan sakit. Perilaku merokok yang dilakukan oleh para perokok di terminal tentu saja dapat menyebabkan sakit. Bahkan, responden menyatakan efek lanjut dari sakit yang disebabkan oleh rokok ini adalah bisa menyebabkan kematian. 
"Ya dampak rokok itu batuk-batuk, bisa mengalami sakit jantung, paru-paru, keguguran, gangguan kehamilan, impotensi, seperti yang tertulis di bungkus rokok itu"

Meskipun informasi yang diketahui hanya sampul rokok. Akan tetapi, ada responden yang menganggap rokok menyebabkan sakit yang berbahaya. Ancaman rokok yang lain adalah kecanduan terhadap rokok.

"Jika dilihat dari sampul rokok yang baru dengan segala macam gambar-gambar nya, seperti bahaya impotensi dan sakit jantung. Merokok menyebabkan kematian. Tetapi kami ini sudah kecanduan terhadap rokok, sudah tidak menghiraukan gambar. Meski telah memiliki niat untuk berhenti, namun ada saja sesuatu hal yang bisa menyebabkan merokok kembali”

Responden mengetahui kandungan yang terdapat dalam rokok. Sebagian besar responden menjawab kandungan rokok adalah nikotin, dan hanya beberapa responden menjawab kandungan rokok adalah tar.

"Apa saja kandungan nya. Misalnya tar dengan nikotin saja setahu saya. Meskipun mengetahui kandungan dari rokok, tetapi tidak ada yang mengetahui bahaya dari kandungan rokok yang disebutkan”

Persepsi masyarakat tentang keuntungan dengan adanya kawasan tanpa rokok

Kawasan tanpa rokok diharapkan menghentikan penjualan rokok, agar kesehatan pengakses terminal tetap terjaga, udara sehat di terminal. Akan tetapi, responden mengharapkan kawasan tanpa rokok yang dimaksud merupakan kawasan yang tidak total KTR.

"Jika terdapat tempat yang bebas yang diperuntukkan untuk perokok, akan lebih bagus lagi”

Meskipun responden mendukung inisiasi kawasan tanpa rokok. Tetapi responden masih memberikan kelonggaran kepada para perokok. Inisiasi kawasan tanpa rokok memerlukan bantuan dari berbagai lintas sektor, seperti dinas kesehata, dinas kebersihan, dan pihak kepolisian sebagai pemberi sanksi.

"Kami kerja sama dengan dinas kesehatan kota, karena ini berkaitan dengan kesehatan, yang menjalankan tetap orang-orang di terminal. Seperti spanduk tentang peraturan tentang rokok, ada upaya juga dari dinas kesehatan, pekeriaan yang mengandung ibadah (inisiasi KTR demi kesehatan orang banyak memang harus ada yang menggerakkan. Karena berkaitan dengan masalah perilaku sangat sulit untuk diubah”

Penerapan KTR membuat terminal menjadi tempat umum pertama yang menerapkan kawasan tanpa rokok meski belum secara menyeluruh. Terminal yang menerapkan KTR dapat berubah menjadi lebih bersih, nyaman dan lingkungan sehat bagi pengguna.
"Peraturan ini bagus terutama untuk anak-anak. Kita dapat memberi contoh untuk anak-anak. Kita membina anak-anak dari kecil, nanti berefek pada masa depan. Mereka menjadi paham merokok tidak baik. Mereka melihat penerapan peraturan. Sudah tidak ada orang yang merokok. Biasanya merokok terjadi karena ada salah satu orang merokok dan ikut-ikutan. Sehingga, tertanam dari usia dini bahwa perilaku merokok adalah sesuatu hal yang tidak baik dan setiap peraturan harus dipatuhi”

Persepsi masyarakat tentang hambatan yang mungkin muncul dalam upaya inisiasi KTR

Responden cenderung merokok setelah makan, intensitas merokok akan lebih sering jika di musim dingin, merokok bersama-sama dengan para petugas terminal yang merokok, tidak mengenal tempat seperti di bus dan di ruang tunggu, ketika merokok bisa menghabiskan banyak batang rokok.

"Ada yang pergi merokok di tempat makan atau tempat minum kopi. Ada juga yang merasa bahwa musim dingin maka akan lebih sering. Jika musim dingin, perasaan dingin maka akan merokok untuk menghangatkan, semakin banyak menghisap rokok untuk menghilangkan rasa dingin"

Perilaku merokok di terminal dianggap hal yang wajar. Merokok dianggap sebagai pelengkap saat berbincang, bahkan merasa tidak lengkap jika tidak tidak mengantongi rokok. Responden merasa mulut menjadi asam jika tidak merokok. Rokok dianggap ssebagai simbol rasa percaya diri dan kejantanan. Faktor yang mendukung unntuk merokok adalah belum ada peraturan pemerintah tentang larangan merokok di terminal, walaupun responden sudah paham tentang bahaya rokok.

"Menurut saya sah-sah saja, selama tidak ada yang melarang, tidak ada peraturan yang mengatakan bahwa dilarang merokok di terminal”

Penjual rokok bebas berjualan dan mudah ditemui di terminal. Keberadaan penjual rokok mendukung perilaku merokok di terminal.

"Jika kami perokok sudah melihat para penjual rokok, sangat tinggi godaan nya untuk merokok bagi kami ini”

Akses merupakan faktor yang sangat berperan dalam perilaku merokok para perokok. Para pedagang mengatakan rokok adalah barang jualan yang cepat laku dan paling banyak dicari oleh para pembeli, baik dari pihak pengunjung terminal, sopir, tukang ojek dan petugas teminal.

"Jika cepat menjual barang dagangan (rokok) maka keuntungan akan segera kita dapat” 
Keadaan yang berkaitan inilah yang menyebabkan perilaku merokok semakin tinggi karena ada yang menyediakan rokok. Responden pengakses terminal belum bisa membedakan antara kawasan tanpa rokok dan kawasan dilarang merokok. Pemahaman awal responden, kawasan dilarang merokok merupakan kawasan tanpa rokok. Meskipun ada beberapa area yang disebutkan bagian dari kawasan tanpa rokok.

"Tempat-tempat yang lain seperti rumah sakit sekolah, puskesmas, POM bensin dan di bank yang menggunakan $A C$ (tempat yang dianjurkan untuk KTR, agar tidak bertambah sakit karena mereka dalam keadaan sakit, sedangkan di bank tidak memiliki jendela atau di kantor-kantor yang menggunakan AC sehingga kedap udara, udara berputar-putar di situ”

Persepsi masyarakat tentang adanya kemampuan untuk menginisiasi KTR

Hal sederhana yang non perokok lakukan adalah menutup mulut dan hidung, dan mengibas-ngibaskan tangan sebagai simbol perasaan terganggu karena asap rokok. Non perokok yang eksplisit menegur perokok adalah ibu dan orang tua. Harapan upaya inisiasi awal kawasan tanpa rokok adalah kawasan tanpa merokok diberlakukan bertahap.

"Saya menegur mereka (perokok), apakah bisa dimatikan dulu rokok nya, kenapa kok tidak bisa sekali menahan diri merokok di mobil, karena ada asap nya”

\section{BAHASAN}

Pengunjung dan pekerja di tempat umum seperti terminal merupakan kelompok rentan paparan asap rokok. Hasil observasi menunjukkan kawasan terminal termasuk kawasan yang memberikan keleluasaan untuk merokok. Paparan asap rokok jika dihirup dalam jangka waktu lama berisiko menimbulkan penyakit, bahkan kematian. Nikotin yang terdapat dalam rokok bisa menyebabkan berbagai macam jenis penyakit (6). Penelitian lain menemukan hubungan antara perilaku merokok dengan kejadian TB paru di kota Banjarmasin (7). Ancaman yang dirasakan (perceived threat of injury or illness) mengacu sejauh mana seseorang berpikir bahwa penyakit atau kesakitan merupakan ancaman untuk dirinya (8).

Rokok mengandung 4.000 bahan kimia, sehingga asap dari rokok adalah salah satu penyebab polusi udara (9). Asap rokok tidak hanya berbahaya untuk perokok saja, namun perokok pasif. Penelitian lain membuktikan paparan asap rokok pada perokok pasif mengandung 2 kali lebih banyak nikotin, 5 kali lebih banyak karbon monoksida, 3 kali lebih banyak tar, dan 50 kali lebih banyak zat kimia berbahaya (8).
Pemerintah harus berperan sebagai pelaku utama dalam menerapkan regulasi. Pengembangan kebijakan perlu melibatkan pihak yang berhubungan langsung dengan institusi yang dituju, sehingga mengarah pada tujuan yang diinginkan dan dapat diterima oleh semua pihak (10). Kerja sama dengan pihak luar memang dibutuhkan dalam menginisiasi kawasan tanpa rokok, mengingat kompetensi petugas terminal yang terbatas.

Pengaruh signifikan kebijakan dirasakan pada saat melibatkan tokoh masyarakat (11). Kebijakan yang telah ditetapkan di daerah bersifat mandatori, sehingga semua pihak baik itu masyarakat, pengelola, karyawan dan pengunjung wajib menaati (12). Pihak kepolisian dilibatkan dalam pembentukkan peraturan sebagai upaya untuk menakuti pelanggar peraturan. Peraturan kawasan bebas rokok ini berlaku untuk semua orang yang ada pada area tersebut (13).

Inisiasi kawasan tanpa rokok di terminal, perlu melibatkan penyuluhan dan pendidikan untuk seluruh komponen masyarakat. Pendidikan kesehatan adalah salah satu bentuk promosi kesehatan. Pendidikan kesehatan yang efektif bergantung pada media dan metode yang tepat (14). Cara mengubah sikap individu, antara lain adopsi, diferensiasi, integrasi, trauma dan generalisasi. Beberapa cara ini diaplikasikan utnuk mencapai hidup sehat tanpa paparan asap rokok (15).

Perilaku merokok sedikit banyak dipengaruhi tata krama. Individu yang tidak memiliki tata karma, cenderung merokok di sembarang tempat, tanpa mempedulikan orang di sekitar. Perilaku merokok ini tidak hanya faktor internal (keinginan pribadi). Perilaku merokok dipengaruhi lingkungan (8). Perilaku merokok dipengaruhi oleh lingkungan teman sebaya (6). Namun, hasil berbeda ditemukan pada penelitian lain. Penelitian tersebut menemukan bahwa faktor yang memengaruhi perilaku merokok bukan faktor eksternal, namun faktor internal seperti kemampuan ekonomi, niat pribadi, dan kepuasan diri (17).

Perilaku merokok umum terjadi karena berbagai alasan. Seseorang memutuskan merokok karena memiliki persepsi rokok mampu menghilangkan stres, memberikan rasa nyaman (rileks) simbol kejantanan, merasa lebih terkenal dan terlihat lebih muda $(2,3)$.

Non perokok mendukung penerapan kebijakan kawasan tanpa rokok daripada perokok. Penelitian lain menemukan kebijakan kawasan tanpa rokok di kampus terbukti dapat mengurangi perokok pasif dan membantu mengatasi masalah rokok (18). Penelitian di Meksiko menemukan perokok mendukung kebijakan kawasan tanpa rokok. Tetapi responden tetap mendukung hak untuk merokok di tempat yang disediakan (19). 
Perokok di terminal Dara mendapatkan rokok dari rumah yang disiapkan selama sebulan. Selain itu, ada yang meminta rokok dari teman kerja. Penelitian lain menemukan ciri perokok berat adalah membekali rokok di rumah dan saat bepergian (8). Green et al. berdasarkan precede model menjelaskan ketersediaan rokok di area terminal Dara kota Bima merupakan enabling factor. Sesama perokok saling berbagi rokok dan menikmati waktu bersama merupakan reinforcing factor yang memperkuat perilaku merokok (20).

Pedagang di terminal mengungkapkan inisiasi kawasan tanpa rokok di terminal belum dibutuhkan. Pedagang beragumen bahwa permintaan rokok masih tinggi. Produkasi rokok di Indonesia dari tahun 2005 terus mengalami peningkatan. Hal ini menunjukkan peningkatan kebutuhan dan permintaan rokok (21).

Pemahaman yang rendah tentang kawasan tanpa rokok berakibat peningkatan jumlah perokok yang merokok di sembarang tempat. Penelitian di Afrika menunjukkan peningkatan pemahaman kebijakan melibatkan tokoh masyarakat seperti ulama (22). Penduduk yang menetap dalam suatu Negara dianggap mengetahui seluruh aturan hukum yang berlaku di sebuah negara, tanpa aturan dan hukum tersebut tidak disosialisasikan secara maksimal (23). Pengendalian tembakau merupakan prioritas promosi kesehatan. Tetapi, perlu inovasi yang sesuai dengan sasaran, budaya, dan bahasa untuk meningkatkan efektivitas kampanye (24).

Para responden memiliki kemampuan menginisiasi kawasan tanpa rokok. Meskipun, orang yang merokok butuh untuk dihargai (self esteem) baik oleh sesama perokok dan bukan perokok. Akan tetapi, perokok bertanggung jawab untuk menciptakan lingkungan sekitar agar lebih sehat. Peraturan harus diwujudkan menjadi peraturan tertulis (26). Proses pembuatan kebijakan diawali dengan dari kepedulian walikota tentang kesehatan masyarakat dan kesepakatan antara lembaga eksekutif dan legislatif (27). Peningkatan kapasitas nasional dalam pengendalian tembakau merupakan sebuah proses menantang.

Pelaksanaan framework convention on tobacco control (FCTC) merupakan bentuk perlindungan generasi dari kesakitan, sosial, lingkungan dan konsekuensi ekonomi dari konsumsi tembakau dan paparan terhadap asap tembakau (28). Peningkatan pajak rokok yang dikombinasikan dengan kebijakan pengendalian tembakau menekan jumlah perokok dan penurunan kematian akibat rokok (29). Pada tingkat daerah, banyak kebijakan dan prioritas yang disetujui bersama, dan hal ini dapat meningkatkan keefektifan kebijakan (30).

\section{SIMPULAN}

Responden memahami bahwa rokok menyebabkan timbulnya penyakit yang serius, bahkan menimbulkan kematian. Keuntungan berupa tidak terpapar asap rokok, dukungan dan kerja sama dengan pihak lain dan bisa menjadi percontohan tempat umum yang memiliki peraturan KTR di kota Bima. Hambatan muncul dari pedagang rokok yang merasa terancam mengingat rokok adalah barang yang sering dicari oleh masyarakat. Program KTR terlaksana dengan asas masyarakat tunduk terhadap kebijakan pemerintah kota, jika peraturan realistis dan disosialisasikan dengan baik kepada masyarakat.

\begin{abstract}
Abstrak
Tujuan: Penelitian untuk mengetahui persepsi pengguna terminal Dara kota Bima mengenai upaya inisiasi kawasan tanpa rokok. Metode: Penelitian kualitatif ini melalui pendekatan fenomenologi. Pemilihan responden secara purposive meliputi petugas terminal, pengunjung dan penjual. Pengumpulan data dilakukan dengan observasi pada bulan Agustus selama 2 minggu dan wawancara mendalam terhadap 20 responden pengguna terminal. Data dianalisis dengan teknik content analysis. Hasil: Masyarakat pengguna terminal memahami bahwa rokok menyebabkan sakit yang serius bahkan menimbulkan kematian, masyarakat diuntungkan dengan adanya KTR di terminal karena dapat mengakses terminal tanpa takut terpapar asap rokok, perlu kerja sama dengan pihak lain untuk mengurangi jumlah perokok di terminal. Hambatan yang muncul adalah perilaku merokok di terminal sudah dianggap biasa dan pedagang rokok merasa terancam. Kawasan tanpa rokok bisa terlaksana jika peraturan tersebut realistis, disosialisasikan dengan baik kepada masyarakat dan masyarakat taat pada peraturan pemerintah. Simpulan: Inisiasi KTR di terminal Dara kota Bima dapat terlaksana jika ada kebijakan tentang KTR, kerja sama dengan pihak terkait dan diikuti dengan kegiatan sosialisasi secara menyeluruh agar masyarakat sebagai pengguna terminal dapat mengetahui dan mematuhi kebijakan KTR yang disepakati.
\end{abstract}

Kata kunci: perilaku merokok; kawasan tanpa rokok; terminal 


\section{PUSTAKA}

1. World Health Organization. Report on the global tobacco epidemic, 2013: enforcing bans on tobacco advertising, promotion and sponsorship [Internet]. Geneva: World Health Organization; 2013. [cited 2015 Jan 12]. 202 p.

2. Liana I, Prabandari YS. Persepsi Mahasiswa terhadap Perilaku Merokok di Kampus Terpadu Politeknik Kesehatan Kemenkes Nanggroe Aceh Darussalam (Doctoral dissertation, [Yogyakarta]: Universitas Gadjah Mada).

3. Song AV, Glantz SA, Halpern-Felsher BL. Perceptions of second-hand smoke risks predict future adolescent smoking initiation. Journal of Adolescent Health. 2009 Dec 1;45(6):618-25.

4. Glanz K, Rimer BK, Viswanath K, editors. Health behavior and health education: theory, research, and practice. John Wiley \& Sons; 2008 Aug 28.

5. Creswell JW. Research design pendekatan kualitatif, kuantitatif, dan mixed. Yogyakarta: Pustaka Pelajar. 2010.

6. Fillon, M. Elektronic cigarettes May Lead to Nicotine Addiction. News.JNCIJ, Natl Cancer 2015;107 (3).Oxford University Press

7. Heriyani, F. Faktor Risiko Lingkungan Rumah, Perilaku Merokok dan Konsumsi Alkohol pada Kejadian TB Di Kota Bnajarmasin. Tesis Gadjah Mada;2012.

8. Santosa IB, Nestopo LR. Ngudud: cara orang Jawa menikmati hidup. Manasuka; 2012.

9. Ahsan A, Wiyono SW, Wibisana W. Dampak Tembakau dan Pengendaliannya di Indonesia. Jakarta: Lembaga Demografi FEUI. Hal. 2009:4-80.

10. Simons-Morton BG, Greene WH, Gottlieb NH. Introduction to health education and health promotion. InIntroduction to health education and health promotion 1995.

11. Ayo-Yusuf OA, Olutola BG, Agaku IT. Permissiveness toward tobacco sponsorship undermines tobacco control support in Africa. Health promotion international. 2014 Dec 18;31(2):414-22.

12. Baron-Epel O, Satran C, Cohen V, Drach-Zehavi A, Hovell MF. Challenges for the smoking ban in Israeli pubs and bars: analysis guided by the behavioral ecological model. Israel journal of health policy research. 2012 Dec;1(1):28.

13. Launay M, Le Faou AL, Sevilla-Dedieu C, Pitrou I, Gilbert F, Kovess-Masfety V. Prevalence of tobacco smoking in teachers following anti-smoking policies: results from two French surveys (1999 and 2005). European journal of public health. 2009 Sep 30;20(2):151-6.

14. Dignan MB, Carr PA. Program planning for health education and promotion. Lea \& Febiger; 1992.
15. Sarwono SW. Psikologi Sosial Kelompok dan Terapan. PT Balai Pustaka; 1999.

16. Otten R, Engels RC, Prinstein MJ. A prospective study of perception in adolescent smoking. Journal of Adolescent Health. 2009 May 1;44(5):478-84.

17. Wahidien. Perilaku Merokok Pengemudi Ojek di Perumahan Taman Telkomas Kota Makassar.Makassar: FKM-Unhas;2013

18. Mardhiah A, Prabandari YS. Dukungan Stakeholders terhadap Kawasan Tanpa Rokok di Lingkungan Kampus Terpadu Politeknik Kesehatan Kemenkes Nanggroe Aceh Darussalam (Doctoral Dissertation, Universitas Gadjah Mada).

19. Thrasher JF, Pérez-Hernández R, Swayampakala K, Arillo-Santillán E, Bottai M. Policy support, norms, and secondhand smoke exposure before and after implementation of a comprehensive smoke-free law in Mexico City. American Journal of Public Health. 2010 Sep;100(9):1789-98.

20. Green LW, Kreuter MW, Deeds SG, Partridge KB, Bartlett E. Health education planning: a diagnostic approach.

21. Kartono M. Atlas Tembakau Indonesia. Jakarta: Badan Khusus Pengendalian Tembakau-Ikatan Ahli Kesehatan Masyarakat Indonesia. 2013.

22. Drope JM. The politics of smoke-free policies in developing countries: Lessons from Africa. CVD Prevention and Control. 2010 Sep 1;5(3):65-73.

23. Ruslan A, Librayanto R. Teori dan panduan praktik pembentukan peraturan perundang-undangan di Indonesia. Rangkang Education \& PuKap Indonesia; 2011.

24. Perusco A, Poder N, Mohsin M, Rikard-Bell G, Rissel C, Williams M, Hua M, Millen E, Sabry M, Guirguis S. Evaluation of a comprehensive tobacco control project targeting Arabic-speakers residing in south west Sydney, Australia. Health promotion international. 2010 Feb 26;25(2):153-65.

25. Palutturi, Sukri. Kesehatan itu Politik, Ed. I, Cet. I, Semarang. Karya Aksara;2010.

26. Fertman CI, Allensworth DD. Health promotion programs: from theory to practice. John Wiley \& Sons; 2010 Apr 19.

27. Gafar A. Evaluasi Proses Penerapan Kebijakan Kawasan Tanpa Rokok di Kota Padang Panjang. Yogyakarta: Universitas Gadjah Mada. 2011.

28. Stillman FA, David AM, Kibria N, Phan HT. Building capacity for implementation of the framework convention for tobacco control in Vietnam: lessons for developing countries. Health promotion international. $2013 \mathrm{Feb}$ 14;29(3):442-53.

29. Near AM, Blackman K, Currie LM, Levy DT. Sweden SimSmoke: the effect of tobacco control policies on smoking and snus prevalence and attributable deaths. The European Journal of Public Health. 2013 Nov 27;24(3):451-8

30. Ewles L, Simnett I. Promoting health: a practical guide. Elsevier Health Sciences; 2003. 